\title{
A novel BACE inhibitor isolated from Eisenia bicyclis exhibits neuroprotective activity against $\beta$-amyloid toxicity
}

\author{
Jung Kwon Lee and Hee-Guk Byun * (D)
}

\begin{abstract}
Alzheimer's disease (AD) is a disturbing and advanced neurodegenerative disease and is characterized pathologically by the accumulation of amyloid beta $(A \beta)$ and the hyperphosphorylation of tau proteins in the brain. The deposition of $A \beta$ aggregates triggers synaptic dysfunction, and neurodegeneration, which lead to cognitive disorders. Here, we found that FF isolated from an eatable perennial brown seaweed E.bicyclis protect against A $\beta$-induced neurotoxicity in neuroblastoma cells stably transfected with two amyloid precursor protein (APP) constructs: the APP695 CDNA (SH-SY5Y-APP695swe). The FF demonstrated strong inhibitory activity for $\beta$-secretase $\left(\mathrm{IC}_{50} 16.1 \mu \mathrm{M}\right)$ and its inhibition pattern was investigated using Lineweaver-Burk and Dixon plots, and found to be non-competitive. Then, we tested whether FF could inhibit production of A $\beta$ in SH-SY5Y-APP695swe. FF inhibited the production of A $\beta$ and soluble-APP, residue of APP from cleaved APP by $\beta$-secretase. Our data show that FF can inhibit the production of A $\beta$ and soluble-APP $\beta$ via inhibition of $\beta$-secretase activity. Taken together these results suggest that FF may be worthy of future study as an anti-AD treatment.
\end{abstract}

Keywords: $\beta$-Secretase inhibitory activity, Eisenia bicyclis ethanol extract, Fucofuroeckol-b, $\beta$-Amyloid, Amyloid precursor protein, Alzheimer's disease

\section{Background}

Alzheimer's disease (AD) is a neurodegenerative disease, and its prevalence is increasing rapidly in the elderly population. Dementia is the most prevalent symptom of $\mathrm{AD}$, which is also characterized by progressive cognitive decline, memory impairment, vast neuronal loss, decline in cholinergic transmission, and the presence of senile plaques. AD is pathologically characterized by the presence of extracellular deposition of plaques comprised of amyloid- $\beta$ (A $\beta)$ peptide and neurofibrillary tangles (NFTs) comprised of hyperphosphorylated-tau protein, accumulating evidence suggests that these abnormal protein deposits are unlikely the causative events in $\mathrm{AD}$ as $A \beta$ plaque or NFT volume poorly correlate with the severity of dementia (Šimić et al. 2016). Moreover, the degree of dementia in postmortem brains of AD patients correlates more closely with the level of soluble

* Correspondence: hgbyun@gwnu.ac.kr

Department of Marine Biotechnology, Gangneung-Wonju National University, Gangneung 25457, Republic of Korea oligomers of $A \beta$ species, especially in hippocampal and cortex regions associated with learning and memory function. $A \beta$ peptides are proteolytic products of the amyloid precursor protein (APP) and are sequentially cleaved by $\beta$ - and $\gamma$-secretases (Murphy and LeVine 2010). Although $A \beta$ peptides of varying length are produced, $A \beta-42$ is considered to be comparatively more amyloidogenic and readily assembles into soluble oligomers and consequent fibril deposits. Instead, $A \beta$ oligomers termed as $\mathrm{A} \beta$-derived diffusible ligands, are thought to induce synaptic loss and progressive cognitive decline in AD (Masters and Selkoe 2012).

Currently, marine plants are intriguing materials as nutraceuticals and pharmaceuticals, given their numerous biological and phytochemical benefits. Marine algae can be classified into three classes based on their pigmentation, namely brown, red, and green algae, which are referred to as Phaeophyceae, Rhodophyceae, and Chlorophyceae, respectively (Khan et al. 2010). Since the 1940s, production of algal polysaccharides has attained commercial significance through their application as thickening and gelling agents for various food and

(c) The Author(s). 2018 Open Access This article is distributed under the terms of the Creative Commons Attribution 4.0 International License (http://creativecommons.org/licenses/by/4.0/), which permits unrestricted use, distribution, and 
industrial applications (Burtin 2003). Researchers have revealed that marine algae-originated compounds exhibit various biological activities, including anticoagulant (Athukorala et al. 2007), anti-viral (Artan et al. 2008), antioxidant (Heo et al. 2005), anti-allergic (Li et al. 2008), anti-cancer (Kong et al. 2009), and anti-inflammatory (Kim et al. 2009) activities, among others. Furthermore, several scientific studies have provided insight into the putative neuroprotective properties of marine algae (Zarros 2009). Eisenia bicyclis (Kjellman) is a perennial brown alga, of the family Laminariaceae. It is extensively distributed in Korea and Japan, and is especially abundant in Ulleung and on Dok Island in Korea. It is frequently used as a dietary alternative for Laminaria japonica, along with Ecklonia stolonifera and Ecklonia cava. This species contains several bioactive components, including phlorotannins, polysaccharides, pyropheophytin, sterol, lipids, tripeptides, and oxylipins (Noda et al. 1989; Kurata et al. 1990; Kousaka et al. 2003; Okada et al. 2004). In particular, phlorotannins produced by the polymerization of phloroglucinol (1,3,5-trihydroxybenzene) (Ragan and Glombitza 1986), have been reported to possess various biological activities, such as antioxidant (Kang et al. 2003), anti-inflammatory (Shin et al. 2006), and $\beta$-secretase1 (BACE1) inhibitory (Jung et al. 2010) activities. Although several reports on the cholinesterase and $\beta$-secretase inhibitory activities of brown algae and their phlorotannins have been reported, the neuroprotective effects of $E$. bicyclis and its phlorotannins on A $\beta$-induced neurotoxicity have not yet been studied. Natural products from brown algae effectively modulate the type of neurodegenerative changes seen in $\mathrm{AD}$, suggesting therapeutic potential. The present work focuses on the chemistry of polyphenols and their role in modulating APP processing. We also provide new hypotheses on how these therapeutic molecules may modulate APP processing, prevent $\mathrm{A} \beta$ aggregation.

Therefore, the aims of this study were to study the potential of $E$. bicyclis and its isolated $\beta$-secretase inhibitor to protect against $A \beta$-induced neurotoxicity, and to reduce $A \beta$ in neuroblastoma cells.

\section{Material and methods}

\section{Sample preparation}

Brown alga (E. bicyclis) was collected from the coast of Ullengdo, Ullengdo Island, South Korea, in July 2013. The samples were washed three times with tap water to remove salt, epiphytes, and sand attached to the surface and then rinsed with fresh water, dried under shade, and homogenized with a grinder.

\section{Preparation of ethanolic extract and fractions}

The algal powder $(1 \mathrm{~kg})$ was extracted with $3 \mathrm{~L}$ of $80 \%$ ethanol at $37^{\circ} \mathrm{C}$ for $24 \mathrm{~h}$ and then filtered. After filtration, the ethanol extracts were dried using a rotary evaporator under vacuum. Each extract was partitioned with organic solvents to yield n-hexane, ethyl acetate, and $\mathrm{H}_{2} \mathrm{O}$ fractions (Fig. 1a).

\section{Isolation of compounds}

The active fraction was purified using a silica gel-filled Sephadex LH-20 (Sigma-Aldrich, MO, USA) chromatography column, and the column was eluted with methanol at a flow rate of $1.5 \mathrm{~mL} / \mathrm{min}$. The isolated fraction from the Sephadex LH-20 column was isolated using a solid phase extraction (SPE) column (Hi-Load $18,5 \mathrm{~g}, 20 \mathrm{~mL}$, Chrom Tech, Inc.) and a thin-layer chromatography (TLC) $(0.25 \mathrm{~mm}$ Silica gel 60 F254, Merck, Co.) preparative separation. The active fraction was separated by high-performance liquid chromatography (HPLC) (Agilent 1100 series, USA) on a C18 ODS column $(4.6 \times 250 \mathrm{~mm}, 5 \mu \mathrm{m}$, Shodex, Tokyo, Japan) at a flow rate of $1.0 \mathrm{~mL} / \mathrm{min}$ at $215 \mathrm{~nm}$.

\section{NMR analysis}

All non-aqueous reactions were performed in flame-dried glassware under a nitrogen atmosphere with magnetic stirring. NMR spectra were obtained on a JOEL Lambda 300 spectrometer and recorded at $300 \mathrm{MHz}$ for ${ }^{1} \mathrm{H}(75$ $\mathrm{MHz}$ for $\left.{ }^{13} \mathrm{C}\right)$ with $\mathrm{CDCl}_{3}$ as a solvent and $\left(\mathrm{CH}_{3}\right)_{4} \mathrm{Si}\left({ }^{1} \mathrm{H}\right)$ or $\mathrm{CDCl}_{3}\left({ }^{13} \mathrm{C}, 77.0 \mathrm{ppm}\right)$ as internal standards, unless otherwise stated. All ${ }^{31} \mathrm{P}$ NMR chemical shifts are reported in ppm relative to $85 \% \mathrm{H}_{3} \mathrm{PO}_{4}$ (the external standard). FT-IR spectra were recorded on a JASCO FR-IR 460 series unit. High-resolution FAB mass spectra were attained from a hybrid LC-quadrapole-TOF tandem mass spectrometer at Gangneung-Wonju National University.

\section{Measurement of $\beta$-secretase inhibitory activity}

$\beta$-Secretase inhibitory activity was measured following Johnston's method (Johnston et al. 2008), using a commercially available fluorogenic substrate, MCA-EVKMD AEFK-(DNP)- $\mathrm{NH}_{2}$. This substrate is analogous to the wild-type APP sequence and is derivatized at its $\mathrm{N}$-terminus with a fluorescent 7-methoxycoumarin-4-yl acetyl (MCA) group and at its $\mathrm{C}$-terminal lysine residue with a 2,4-dinitrophenyl (DNP) group. In the whole peptide, the fluorescence of the MCA group is eliminated by internal quenching from the DNP group. Once cleaved by $\beta$-secretase activity, the MCA fluorescence can be detected. Tests were carried out in 96-well black plates using a spectrofluorometer (Tecan, Switzerland). $\beta$-Secretase and $\beta$-secretase substrate I were incubated in a final volume of $200 \mu \mathrm{L}$ of assay buffer $(50 \mathrm{mM}$ sodium acetate, $\mathrm{pH} 4.5)$. The hydrolysis of $\beta$-secretase substrate I was followed at 37 ${ }^{\circ} \mathrm{C}$ for $30 \mathrm{~min}$ by measuring the associated increase in fluorescence. Readings (excitation $325 \mathrm{~nm}$, emission $393 \mathrm{~nm}$ ) were obtained every $60 \mathrm{~s}$. The inhibition ratio was calculated using the following equation: inhibition $(\%)=[1-\{(S$ 


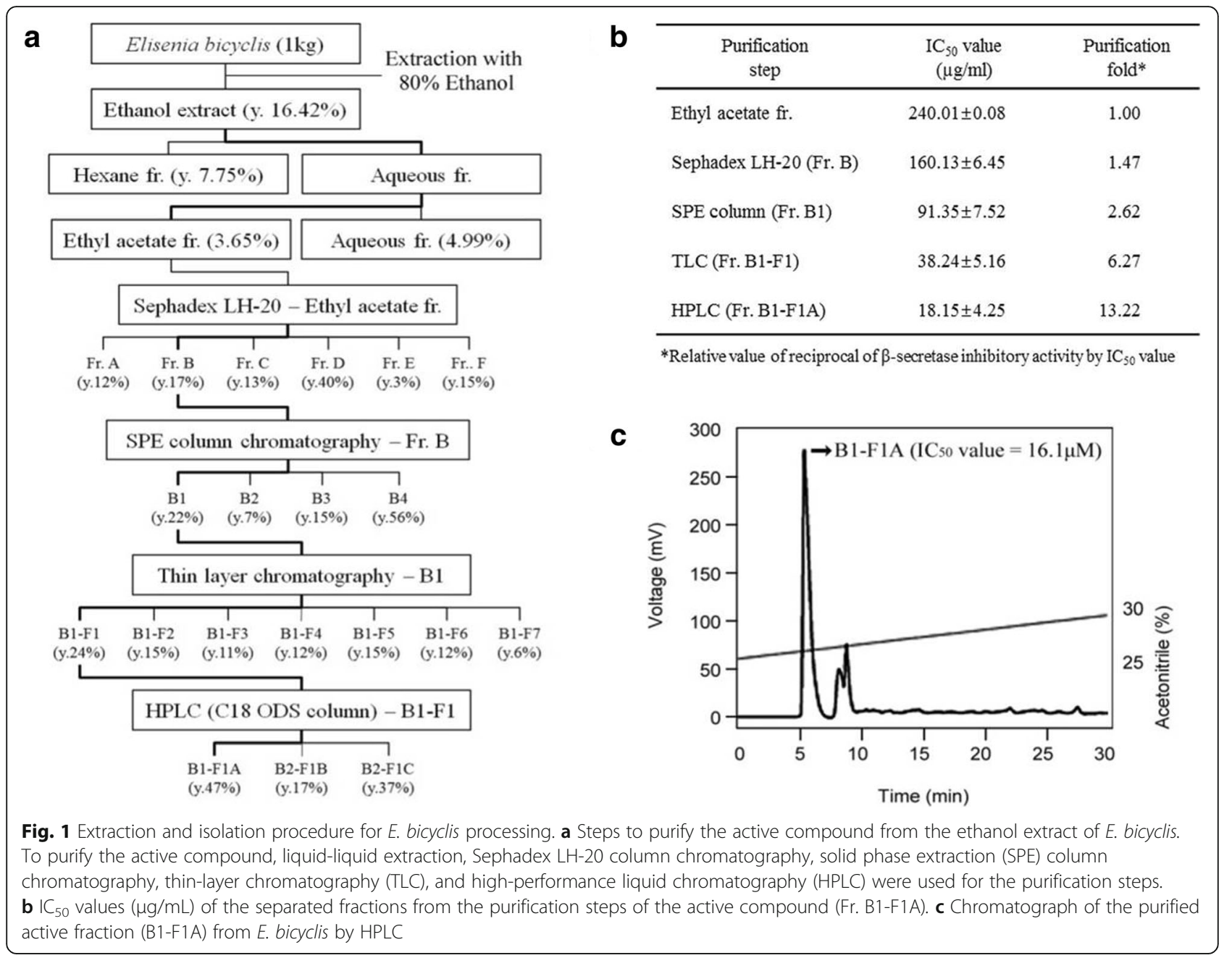

$-S O) /(C-C O)\} \times 100]$, where $C$ is the fluorescence of a control (enzyme, assay buffer, and substrate) after $60 \mathrm{~min}$ of incubation, $\mathrm{CO}$ is the fluorescence of the control at zero time, $S$ is the fluorescence of test samples (enzyme, sample solution, and substrate) after $60 \mathrm{~min}$ of incubation, and $S O$ is the fluorescence of the relevant test sample at zero time. All data are the mean of triplicate experiments.

\section{Kinetic analysis}

To investigate the mode of $\beta$-secretase inhibition by the purified inhibitor, the purified inhibitor was added to each reaction mixture. The inhibition constants $(K i)$ of $\beta$-secretase inhibitors were calculated using Dixon plots. To determine the kinetics of purified compounds, inhibition rates were measured at four concentrations of the substrate $(500,750,1000$, and $1500 \mathrm{nM})$. For the Dixon plots, data were acquired as mean values of $1 / \mathrm{V}$ (reaction velocity), the inverse of the intensification of fluorescence intensity per $\min (\mathrm{min} /$ relative fluorescence units, RFU) of three independent tests with different concentrations
$(0,2.5,5.0$, and $10 \mu \mathrm{M})$ of inhibitor. The assay was carried out in the presence of purified inhibitor.

\section{Cell culture}

Human neuroblastoma SH-SY5Y cells were maintained in Dulbecco's modified Eagle medium nutrient mix F12 medium (GIBCO, Carlsbad, CA, USA) containing L-glutamine and $15 \mathrm{mM}$ HEPES, supplemented with $10 \%$ fetal bovine serum (GIBCO, Carlsbad, CA, USA) and $100 \mathrm{U} / \mathrm{mL}$ penicillin-streptomycin at $37^{\circ} \mathrm{C}$, under $5 \% \quad \mathrm{CO}_{2}$. SH-SY5Y-APP695swe cells stably transfected with the human Swedish mutation were generated as previously described (Jämsä et al. 2011). The cDNA encoding human APP695swe was inserted into the expression vector pIREShyg (Clontech) before being stably transfected into SH-SY5Y cells. DNA $(30 \mu \mathrm{g})$ was introduced into the cells by electroporation in 4-mm cuvettes with a pulse of $250 \mathrm{~V}$ and $1650 \mu \mathrm{F}$ using an ECM630 electroporator (BTX Harvard Apparatus, Holliston, MA). Selection for cells containing the required construct was performed in 
normal growth medium with $0.15 \mathrm{mg} / \mathrm{mL}$ hygromycin B (Invitrogen, Paisley, UK). Cells were grown to $90-100 \%$ confluency, washed twice with phosphate-buffered saline solution (pH 7.4, GIBCO, Carlsbad, CA, USA), and incubated in $10 \mathrm{~mL}$ of serum-free Opti-MEM (Invitrogen, ON, USA) for $24 \mathrm{~h}$. The conditioned medium was harvested, and $5 \mathrm{~mL}$ was concentrated to $200 \mu \mathrm{L}$ using $10-\mathrm{kDa}$ cutoff Vivaspin filtration columns (Millipore, Billerica, MA). The remaining 5-mL conditioned media sample from the SH-SY5Y cells was used for analysis of A $\beta 42$ using an ELISA kit (Invitrogen, ON, USA).

\section{A $\beta$-induced toxicity on SH-SY5Y cells}

On the experiment day, the culture media were removed, and cells were incubated at $37^{\circ} \mathrm{C}$ in fresh culture media and exposed to either $A \beta 42$ for $24 \mathrm{~h}$, in the presence or absence of a $\beta$-secretase inhibitor. A $\beta 42$ was dissolved by briefly vortexing in distilled water containing ammonium hydroxide $0.02 \%(v / v)$ and stored at $-20^{\circ} \mathrm{C}$ before use. Cells were also treated with the inactive reverse sequence peptide $A \beta 42$ to confirm the specificity of the toxic effects of the fragment $A \beta 42$. Cell viability was assessed $24 \mathrm{~h}$ later using the 3-(4,5-dimethylthiazol-2-yl)-2,5-diphenyl tetrazolium bromide (MTT) colorimetric assay.

\section{MTT assay}

To evaluate the toxicity of the active sample, cells were seeded in 96-well plates $\left(5 \times 10^{4}\right.$ cells $\left./ \mathrm{mL}\right)$ and incubated with varying sample concentrations $(6.5,15,25$, and $50 \mu \mathrm{M})$ for $24 \mathrm{~h}$. The cell culture media were changed immediately before the MTT assay to avoid interaction between MTT and the sample, and $10 \mu \mathrm{L}$ MTT $(5 \mathrm{mg} /$ $\mathrm{mL}$, Sigma-Aldrich, MO, USA) solution was added, followed by incubation for $4 \mathrm{~h}$. The supernatant was removed, and $100 \mu \mathrm{L}$ DMSO was added to dissolve the dye crystals. Absorbance was read at $490 \mathrm{~nm}$, and the percentage of viable cells was calculated.

\section{Western blot}

Cells were harvested, and proteins were prepared by direct extraction on ice in Tricine sample buffer (Bio-Rad Laboratories, Hercules, CA, USA) containing a protease inhibitor cocktail (Roche, Indianapolis, IN, USA), followed by centrifugation at $4{ }^{\circ} \mathrm{C}$ for $5 \mathrm{~min}$. The supernatant protein concentration was measured using a BCA Protein Assay Kit (Thermo Scientific, Waltham, MA, USA). The protein samples were aliquoted and then frozen at $-80^{\circ} \mathrm{C}$. Approximately $40 \mu \mathrm{g}$ of total protein was loaded into the wells in $8-12 \%$ sodium dodecyl sulfate (SDS)-polyacrylamide gels for determination of full-length APP or in 16\% SDS-Tricine polyacrylamide gels for sAPP $\beta$ and A $\beta$ blots. Afterward, the proteins were transferred onto polyvinylidene fluoride (PVDF) membranes (Millipore, Billerica, MA, USA). After protein transfer, the PVDF membranes were blocked with $5 \%$ dry nonfat milk in Tris-buffered saline plus $0.05 \%$ Tween-20 (TBST) for $1 \mathrm{~h}$ at room temperature and then incubated with primary antibodies against the C-terminus of APP (1:2000, A8717), sAPP $\beta$ $(3 \mu \mathrm{g} / \mathrm{mL}$, SIG-39138), A $\beta$ (1:1000, B-4, Santacruz Biotech), and $\beta$-actin (1:2000, Sigma-Aldrich, MO, USA) in TBST containing $5 \%$ dry nonfat milk overnight at $4{ }^{\circ} \mathrm{C}$ and then for $30 \mathrm{~min}$ at room temperature. The membranes were washed with TBST and incubated with horseradish peroxidase-conjugated secondary antibodies for $2 \mathrm{~h}$ at room temperature. The immunoreactive proteins were detected with ECL Advance Western Blotting Detection Reagents (Amersham Biosciences, Piscataway, NJ, USA). All bands were standardized to $\beta$-actin and then compared and quantified with ImageJ software (National Institutes of Health, Bethesda, MD, USA).

\section{Statistical analyses}

Data were analyzed for statistical significance using analysis of variance (ANOVA) followed by Dunnett's multiple comparison test with SPSS software (version 14). All values obtained from three different experiments were expressed as the mean value \pm SEM.

\section{Results and discussion}

Isolation of a $\beta$-secretase inhibitor using ethanol extraction and partitioning into solvent fractions

A novel $\beta$-secretase inhibitor from $E$. bicyclis was purified using multiple purification methods include organic solvent extraction, LH-20 Sephadex chromatography, thin layer chromatography (TLC), solid phase extraction (SPE) and high performance chromatography (Fig. 1a). Among the fractions separated, the active fractions were selected through $\beta$-secretase inhibitory activity assay.

As shown in Table 1, ethanol extract or its fractions isolated by hexane, ethyl acetate and $\mathrm{H} \mathrm{O}$ fraction exhibited $\beta$-secretase inhibitory activity with an $\mathrm{IC}_{50}$ value of $0.70,1.02,0.24$ and $2.12 \mathrm{mg} / \mathrm{mL}$, respectively. Among the fractions, the ethyl acetate fraction had the highest $\beta$-secretase inhibitory activity.

The ethyl acetate fraction was separated on a silica gel-filled Sephadex LH-20 column into six fractions (A-F). Among the separated fractions, fraction $\mathrm{B}$ had the highest $\beta$-secretase inhibitory activity, with an $\mathrm{IC}_{50}$ value

Table $1 \mathrm{IC}_{50}$ values of $\beta$-secretase inhibitory activity of the ethanol extract and its individual fractions from E. bicyclis

\begin{tabular}{ll}
\hline Sample & $I_{50}$ value $(\mathrm{mg} / \mathrm{mL})^{*}$ \\
\hline Ethanol extract & $0.70 \pm 0.21^{\mathrm{b}}$ \\
Hexane fraction & $1.02 \pm 0.11^{\mathrm{c}}$ \\
Ethyl acetate fraction & $0.24 \pm 0.08^{\mathrm{a}}$ \\
$\mathrm{H}_{2} \mathrm{O}$ fraction & $2.12 \pm 0.27^{\mathrm{d}}$
\end{tabular}

*Values (mean \pm S.E.M. of three replications) not sharing a common superscript letter are significantly different $(p<0.05)$ 
of $0.16 \mathrm{mg} / \mathrm{mL}$ (Fig. 1b). Fraction B from the Sephadex LH-20 column was then purified using an SPE column. In addition, that purified fraction was further isolated using a TLC preparative separation. The TLC purification was carried out in developing solvent (n-Hexane-ethyl-acetate-acetone $(6: 5: 1, \mathrm{v} / \mathrm{v}))$ and scanned under wavelength UN light $(365 \mathrm{~nm})$. Finally, an active fraction, B1-F1A, was purified from the B1-F1 fraction from TLC separation by HPLC. The $\beta$-secretase inhibitory activity of B1-F1A was purified over 13.2-fold from the ethyl acetate fraction using a purification of five steps (Fig. 1b). The purified fraction possessed $\beta$-secretase inhibitory activity with an $\mathrm{IC}_{50}$ value of $16.1 \mu \mathrm{M}$ (Fig. 1c) and exhibited a molecular weight of $478.054 \mathrm{Da}$ according to Q-TOF-MS (data not shown). The structure of the purified fraction B1-F1A was identified by comparing its NMR spectral data with those in the existing literature.

\section{Identification of compounds isolated from E. bicyclis}

Figure 2 shows the spectroscopic properties of the purified fraction, B1-F1A: $\mathrm{C}_{24} \mathrm{H}_{14} \mathrm{O}_{11} ; 1 \mathrm{H}-\mathrm{NMR}(300 \mathrm{MHz}$, DMSO- $\left.d_{6}\right) \delta 11.58(1 \mathrm{H}, \mathrm{s}, 14-\mathrm{OH}), 10.05(1 \mathrm{H}, \mathrm{S}, 4-\mathrm{OH})$, $9.88(1 \mathrm{H}, \mathrm{s}, 10-\mathrm{OH}), 9.45(1 \mathrm{H}, \mathrm{s}, 2-\mathrm{OH}), 9.11(2 \mathrm{H}, \mathrm{s}, 3$ ' $\left.5^{\prime}-\mathrm{OH}\right), 8.22(1 \mathrm{H}, \mathrm{s}, 8-\mathrm{OH}), 6.71(1 \mathrm{H}, \mathrm{s}, \mathrm{H}-13), 6.48(1 \mathrm{H}$, $\mathrm{d}, \mathrm{J}=1.1 \mathrm{~Hz}, \mathrm{H}-11), 6.34(1 \mathrm{H}, \mathrm{s}, \mathrm{H}-3), 6.38(1 \mathrm{H}, \mathrm{d}, \mathrm{J}=$ $1.5 \mathrm{~Hz}, \mathrm{H}-9), 5.86\left(1 \mathrm{H}, \mathrm{s}, \mathrm{H}-4{ }^{\prime}\right), 5.83(2 \mathrm{H}, \mathrm{d}, \mathrm{J}=1.5 \mathrm{~Hz}$, H-2, 6'); 13C-NMR (300 MHz, DMSO- $\left.d_{6}\right) \delta 160.22$ (C-1'), $158.81\left(\mathrm{C}-3,5^{\prime}\right), 158.23$ (C-11a), $157.62(\mathrm{C}-10)$, 150.46 (C-12a), 150.33 (C-8), 146.46 (C-2), 144.33 (C-14), 141.56 (C-4), 136.82 (C-15a), 133.63 (C-5a), 123.58 (C-14a), 122.4 (C-4a), 122.04 (C-1), 103.13 (C-6), 102.48 (C-7), 98.43 (C-3), 98.23 (C-9), 96.6 (C-4'), 96.14 (C-13), 93.2, (C-2',6') 90.68 (C-11).

The molecular structure of the purified compound $\mathrm{C}_{24} \mathrm{H}_{14} \mathrm{O}_{11}$ based on the NMR spectra data is shown in Fig. 2a, b. The proton NMR $\left({ }^{1} \mathrm{H}-\mathrm{NMR}\right)$ spectrum
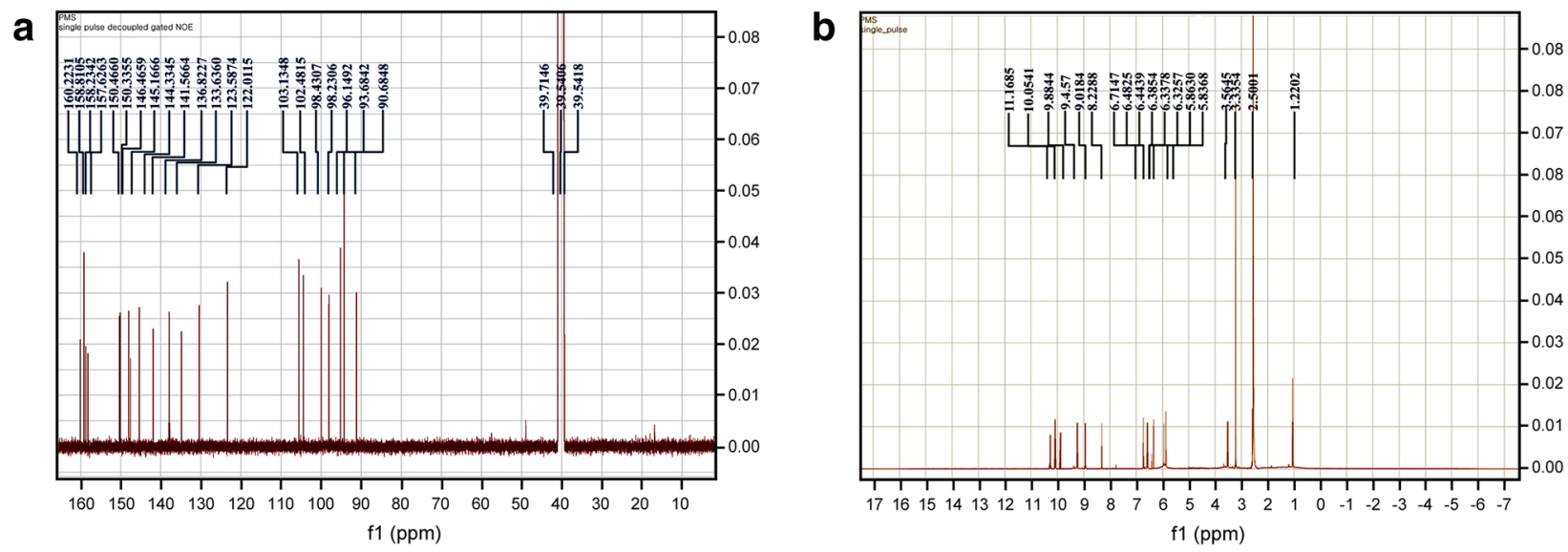

C

\begin{tabular}{cc|cc}
\hline Carbon & B1-F1A fraction & Carbon & B1-F1A fraction \\
\hline 1 & 122.04 & 1 & 158.28 \\
2 & 146.46 & 2 & 150.46 \\
3 & 98.43 & 3 & 96.60 \\
4 & 141.56 & 4 & 144.33 \\
$4 \mathrm{a}$ & 122.40 & $4 \mathrm{a}$ & 123.58 \\
$5 \mathrm{a}$ & 133.63 & $5 \mathrm{a}$ & 136.82 \\
6 & 103.13 & 6 & 160.22 \\
7 & 102.48 & 7 & 93.20 \\
8 & 150.33 & 8 & 158.81 \\
9 & 98.23 & 9 & 96.14 \\
10 & 157.62 & 10 & 158.23 \\
11 & 90.68 & 11 & 93.20 \\
\hline
\end{tabular}

d<smiles>Oc1cc(O)cc(Oc2c(O)cc(O)c3c2Oc2c(cc4oc5cc(O)cc(O)c5c4c2O)O3)c1</smiles>

Fucofuroeckol-b (M.W. 478.054Da)

Fig. $2{ }^{13} \mathrm{C}-\mathrm{NMR}$ spectrum (a) and ${ }^{1} \mathrm{H}-\mathrm{NMR}$ spectrum $(\mathbf{b})$ of fraction B1-F1B in DMSO- $d_{6} . \mathbf{c}{ }^{13} \mathrm{C}-\mathrm{NMR}$ data for the isolated fraction B1-F1B in DMSO$d_{6}$. $\mathbf{d}$ Structure of the isolated fraction B1-F1B from E. bicyclis. The isolated fraction B1-F1B was identified as fucofuroeckol-b (FF) based on the NMR spectra results 
contained signals characteristic of active aromatic protons. AB2 system had signals at $\delta-6.71(1 \mathrm{H}, \mathrm{s})$ and 6.47 $(1 \mathrm{H}, \mathrm{d}, \mathrm{J}=1.10 \mathrm{~Hz}), \delta 6.25(1 \mathrm{H}, \mathrm{d}, \mathrm{J}-1.46 \mathrm{~Hz})$ and 5.76 $(2 \mathrm{H}, \mathrm{d}, \mathrm{J}=1.46 \mathrm{~Hz})$, and two singlets at $\delta 6.29(1 \mathrm{H}, \mathrm{s})$ and $5.83(1 \mathrm{H}, \mathrm{s})$, as well as eight phenolic hydroxyl signals at $810.05,9.88,9.76$, and 8.22 . The carbon-13 nuclear magnetic resonance $\left({ }^{13} \mathrm{C}-\mathrm{NMR}\right)$ spectrum of the purified compound indicated the presence of 7 methanes, 15 O-bearing aromatic carbons, and 2 quaternary carbons $(\delta 103.1,102.4)$. The compound is composed of four benzene rings that are joined together via a furanoid, a 1,4 dioxin structure, and a phenyl ether bridge. The chemical shifts of C-5a, C-13, C-14, and C-14a were very close to those of the subsequent signals of eckol, and those of the two other carbons [C-6 ( 8103.1$)$ and C-12a $(\delta 150.5)]$ were different from the subsequent signals.

Thus, the purified compound had to be an eckol switched with phloroglucinol via a biaryl bond at C-9. The removal of one molecule of water from the hydroxyl groups at C-2 of the phloroglucinol and C-8 of the eckol unit must then have caused the creation of the furan ring. These data indicate that this compound contains an eckol moiety and that $\mathrm{C}-12 \mathrm{a}$ or $\mathrm{C}-13$ can be altered or can exist close to the variation. Therefore, the purified compound was identified as fucofuroeckol-b (FF) based on the NMR spectrum results.

$\mathrm{FF}$ was first isolated as its free form from natural sources from E. bicyclis, although the hepta-acetate of FF has been previously isolated from Eisenia arborea (Glombitza and Gerstberger 1985). The $\beta$-secretase inhibition pattern of $\mathrm{FF}$ from $E$. bicyclis was investigated using Lineweaver-Burk plots and Dixon plots, and it was found to be non-competitive (Fig. 3a). Thus, it could bind with both the enzyme and the enzyme-substrate complex and interact independently of the substrate. In addition, the inhibitor did not change the substrate-enzyme binding affinity. With increasing concentrations, a sequence of lines was observed that had a shared intercept on the $1 /[\mathrm{S}]$ axis but different slopes. To determine the manner of $\beta$-secretase inhibition, kinetic analysis was performed using different substrate $(500,750,1000$, and $1500 \mathrm{nM})$ and inhibitor concentrations. The inhibition constants (Ki) were obtained by analysis of the Dixon plots, in which the value of the $x$-axis denoted $K i$. The Dixon plot is a graphical approach [plot of 1 /enzyme velocity $(1 / \mathrm{V})$ against inhibitor concentration] to determine the type of enzyme inhibition, and it can be used to determine the dissociation or $\mathrm{Ki}$ for the enzyme-inhibitor complex (Cornish-Bowden and Eisenthal 1974). In the case of competitive inhibition, the $x$-axis indicates $K i$ when $1 / \mathrm{V}=1 /$ Vmax. In non-competitive inhibition, the $x$-axis indicates $K i$ when $1 / \mathrm{V}=0$. As shown in Fig. 3b, FF $(K i=10.1)$ showed a non-competitive inhibition pattern in the Dixon plots. Typically, the lower the $K i$ value, the stronger the binding with the enzyme, and the more efficient an inhibitor is; thus, the results indicated that FF may be a strong candidate for a $\beta$-secretase inhibitor. Jung et al. (2010) reported that various phlorotannins demonstrated significant and non-competitive inhibition against $\beta$-secretase: dioxinodehydroeckol $\quad(K i=8.0), \quad$ eckol $\quad(K i=13.9)$; phlorofurofucoeckol-A $(K i=1.3)$, triphloroethol-A $(K i=$ $12.1)$, and 7-phloroethol $(K i=7.2)$. The $K i$ value of FF was higher than that of eckol and triphloroethol but lower than that of phlorofurofucoeckol-A. However, they all exhibited a non-competitive inhibition pattern. The E. bicyclis extract and the phlorotannins contained in it likely have value for the development of therapeutic and preventive agents for $\mathrm{AD}$.

\section{Cell cytotoxicity of FF in neuronal cells}

We tested the toxicity of compound FF on SH-SY5Y cells overexpressing APP695swe. Cells were treated with increasing concentrations of FF $(15,25,50$, and $100 \mu \mathrm{g} /$ $\mathrm{mL}$ ) for $24 \mathrm{~h}$, and cell viability was assessed by MTT assay. Cells treated with concentrations of the compound up to $15 \mu \mathrm{g} / \mathrm{mL}$ did not exhibit reduced viability,
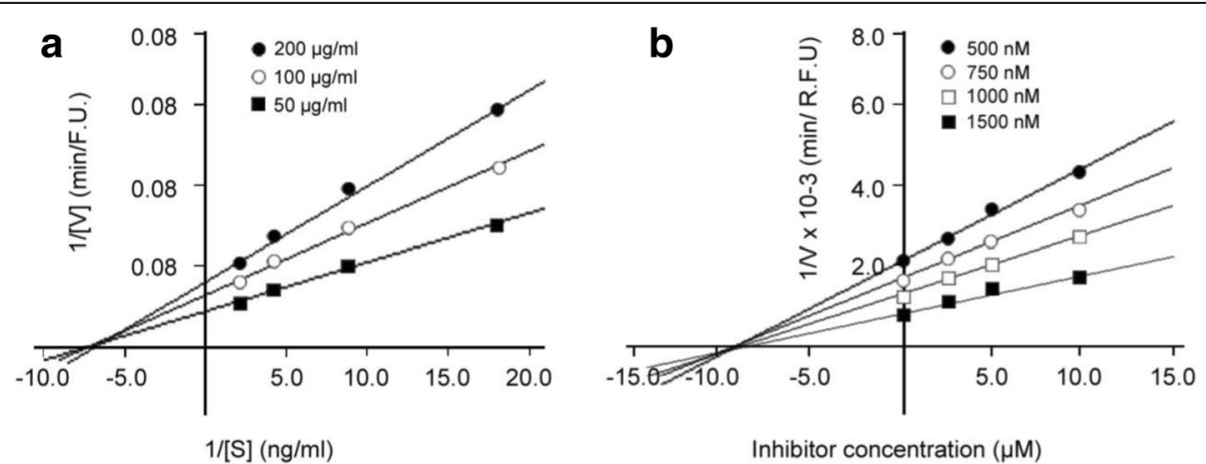

Fig. 3 a Lineweaver-Burk plots for the inhibition of $\beta$-secretase in the presence of FF. Concentrations of FF for the curves were 50, 100, and $200 \mu \mathrm{g} / \mathrm{mL}$, using the substrate as the control. b Dixon plots for the inhibition of $\beta$-secretase by FF in the presence of different concentrations of the substrate: $500 \mathrm{nM}$ (black circle), $750 \mathrm{nM}$ (white circle), $1000 \mathrm{nM}$ (white square), and $1500 \mathrm{nM}$ (black square) 
a

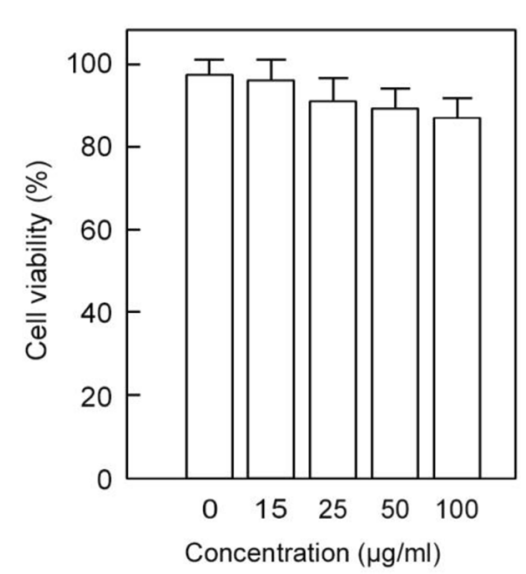

c
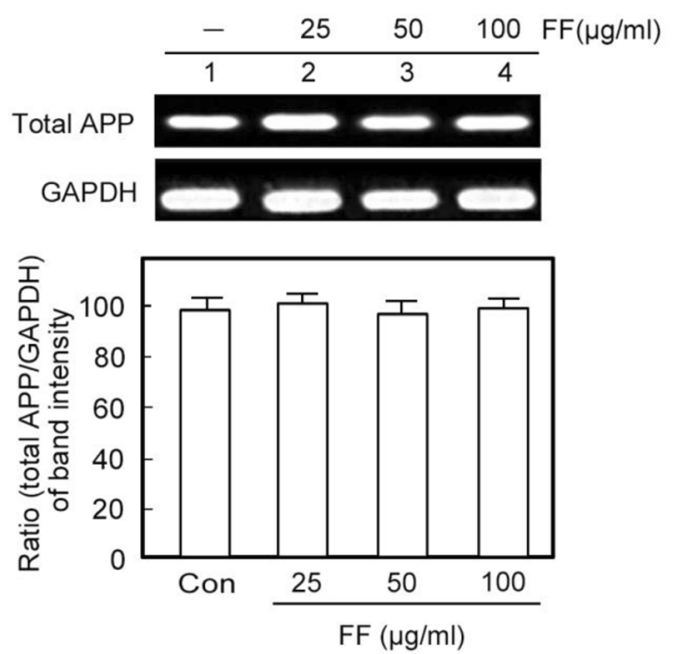

e

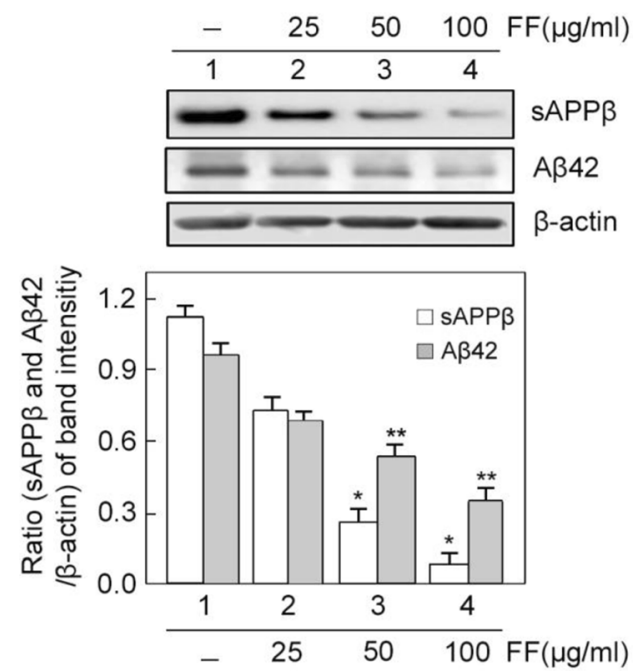

b

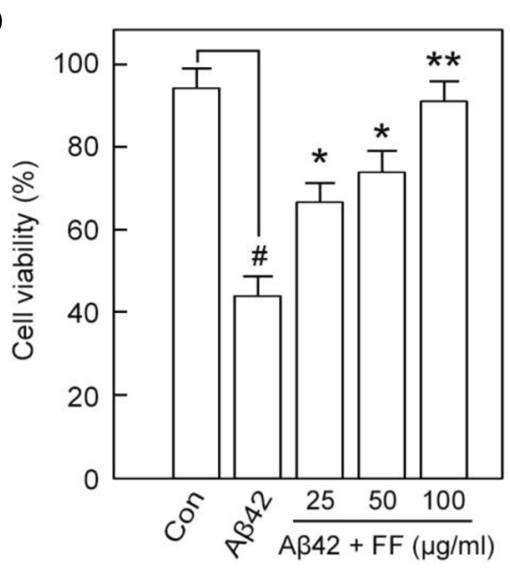

d
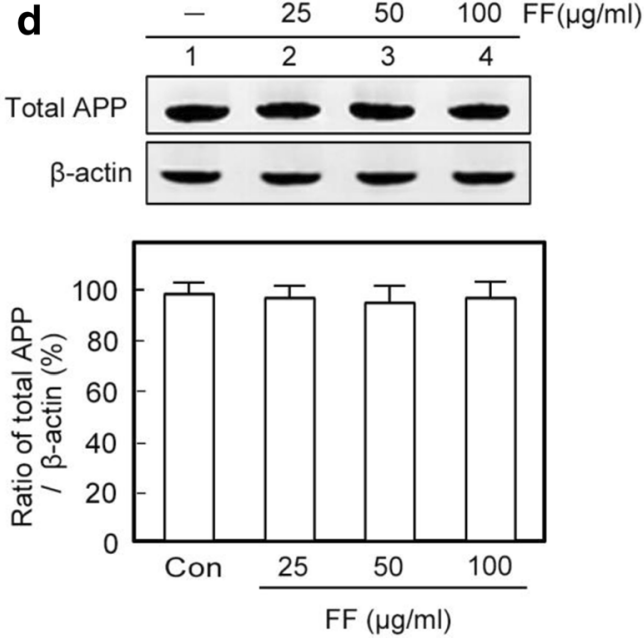

\section{f}

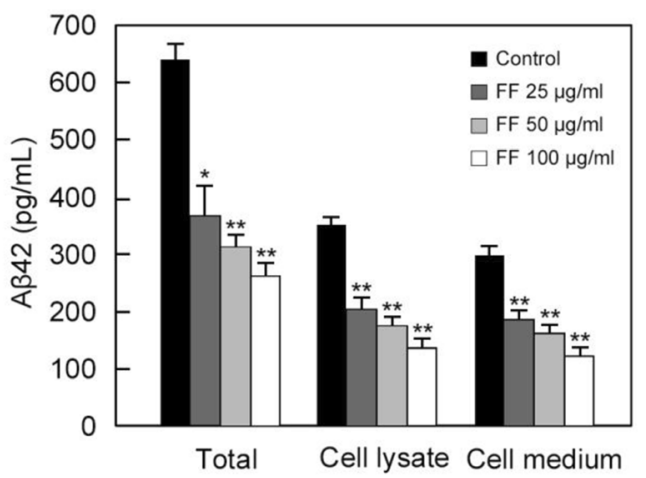

Fig. 4 (See legend on next page.) 
(See figure on previous page.)

Fig. 4 Cytotoxicity of a SH-SY5Y cells overexpressing APP695swe that were treated with FF (0, 15, 25, 50, and $100 \mu \mathrm{g} / \mathrm{mL})$ for $24 \mathrm{~h}$. b Effects of purified FF on A 42 -induced cytotoxicity in SH-SY5Y cells. Cells were exposed to various concentrations of FF $(25,50$, and $100 \mu \mathrm{g} / \mathrm{mL}) \mathrm{for} 24 \mathrm{~h}$. After pretreatment, cells were treated with $\mathrm{A} \beta 42(5 \mu \mathrm{M})$ for $24 \mathrm{~h}$, and cell viability was determined by MTT assay. ${ }^{*} P<0.05$; ${ }^{* *} P<0.01$ versus A 42 -treated cells. ${ }^{P} P<0.01$ versus A 42 non-treated cells. c FF treatment did not alter APP expression levels. SH-SY5Y cells overexpressing APP695swe were treated with increasing concentrations of FF $(25,50$, and $100 \mu \mathrm{g} / \mathrm{mL})$ for $24 \mathrm{~h}$. The expression of full-length APP was determined by both RT-PCR and western blotting analysis. The levels of APP mRNA (c) and protein (d) did not significantly differ between control and FF-treated cells. Results are shown as the mean \pm SEM of experiments performed in triplicate $(n=3)$. e Expression levels of SAPP $\beta$ and A 42 in SH-SY5Y-APP695swe cells treated with Leu-Asn peptide measured by western blot analysis. f FF reduced A 342 levels in both cell culture medium supernatants and cell lysates. SH-SY5Y cells overexpressing APP695swe were treated with increasing concentrations of FF $(25,50$, and $100 \mu \mathrm{g} / \mathrm{mL})$ for $24 \mathrm{~h}$. A 442 levels were determined using $A \beta 40-$ and $A \beta 42-$ specific sandwich ELISAs. Total $A \beta 42$ was the sum of $A \beta 42$ in the supernatant and lysate. Results are expressed in picogram per milliliter, and all experiments were performed in triplicate $(n=3) .{ }^{*} P<0.05,{ }^{* *} P<0.01$ compared with the control

nor was cell toxicity observed at concentrations of 50 and $100 \mu \mathrm{g} / \mathrm{mL}$ (Fig. 4a). As illustrated in Fig. 4b, A $\beta 42$ (5 $\mathrm{MM}$ for $24 \mathrm{~h})$ treatment decreased SH-SY5Y cell viability to $47.5 \pm 0.5 \%$, while FF $(25,50$, and $100 \mu \mathrm{g} / \mathrm{mL})$ treatment prevented A $\beta 42$-induced damage, restoring cell survival to $66.9 \pm 1.6 \%, 80.7 \pm 2.5 \%$, and $98.0 \pm 1.3 \%$ (mean \pm S.E.M., $n=3$ ), respectively.

Diverse pathologies and etiologies are involved in neurodegenerative disorders, including AD. A growing body of data suggests free radical-induced toxicity, oxidative impairment, mitochondrial dysfunction, and inflammatory mechanisms may represent common aspects in the pathogenesis of neurodegeneration (Crouch et al. 2008). Among the brain's cells, microglia have been reported to play important roles in neuropathological conditions. In response to a variety of neurotoxic stimuli, microglia become active and secrete a number of pro-inflammatory cytokines and cytotoxic molecules, including ROS and reactive nitrogen species (RNS) (Durrenberger et al. 2012). Conversely, vitamin $\mathrm{E}$ and minocycline have been shown to exhibit neuroprotective roles by inhibiting microglial activation (Ryu et al. 2004). Therefore, in this study, we examined the protective effect of FF, a major constituent of brown algae polyphenolics, against A $\beta$-induced oxidative cell death in SH-SY5Y neuroblastoma cells. We initially examined A $\beta$-induced cytotoxicity in SH-SY5Y cells with an MTT reduction assay. A $\beta$ decreased cell viability in SH-SY5Y cells, though this damage was effectively attenuated in the presence of FF. The molecular mechanisms of A $\beta$-mediated neurotoxicity are not completely understood, but this finding suggested that $\beta$-secretase inhibitor, FF rescues cell death induced by $A \beta$ may rely on inhibition $\beta$-secretase-mediated downregulation of $A \beta$.

\section{Inhibition of amyloidogenic APP processing in SH-SYSY- APP695swe cells}

Human neuroblastoma SH-SY5Y-APP695swe cells overexpressing APP were treated with 25, 50, and $100 \mu \mathrm{g} / \mathrm{mL} \mathrm{FF}$, and APP expression was determined via RT-PCR and western blot analysis (Fig. $4 \mathrm{c}$ and d). As shown in Fig. 4c and d, treatment with 25, 50, and
$100 \mu \mathrm{g} / \mathrm{mL}$ FF did not induce significant changes in APP levels compared to those in the control. We then examined whether FF affected $A \beta$ production, we measured soluble-APP $\beta$ (sAPP $\beta$ ) and A $\beta 42$ levels produced in SH-SY5Y-APP695swe cells after administration of FF at different concentrations for $24 \mathrm{~h}$. The western blot results indicated that FF treatment decreased $\mathrm{SAPP} \beta$ and $A \beta 42$ expression in a dose-dependent manner in SH-SY5Y-APP695swe cells (Fig. 4e).

Both the culture medium supernatants and cell lysates were collected, and $A \beta$ concentrations were determined by ELISA. Total $A \beta$ was the sum of $A \beta$ in the supernatant and lysate. FF significantly decreased $A \beta$ in both the lysate of SH-SY5Y-APP695swe cells and the cell culture supernatant in a dose-dependent manner (Fig. 4f). $\mathrm{A} \beta$ production is likely a primary event in the pathogenesis of $\mathrm{AD}$; therefore, understanding the manner in which APP and the secretases are brought together could provide needed data for designing therapeutic strategies for AD. Previous studies have shown that synthesized peptides such as OM99-2 and KMI 420 bind to $\beta$-secretase and prevent its access to APP, thereby reducing $A \beta$ generation. However, the molecular mechanisms by which APP and $\beta$-secretase come in close proximity to each other in transient or stable complexes are essentially unknown (Ghosh et al. 2012). In this study, we demonstrated that FF strongly reduced $\beta$-secretase cleavage of APP and A $\beta$ generation in a transgenic SH-SY5Y cell line.

\section{Conclusions}

We have attempted purification of a novel $\beta$-secretase inhibitor, FF from marine brown algae, E. bicyclis extracts for the first time. FF exhibited the strongly inhibitory activity against $\beta$-secretase and $A \beta$ production on in-vitro. We have characterized this $\beta$-secretase inhibitor to aid the development of a novel anti-AD treatment for the drug or food supplement industries.

\section{Abbreviations}

AD: Alzheimer's disease; ANOVA: Analysis of variance; APP: Amyloid precursor protein; $A \beta$ : $\beta$-Amyloid peptide; BACE1: The $\beta$-site APP-cleaving enzyme; BCA: Bicinchoninic acid; DMSO: Dimethyl sulfoxide; DNA: Deoxyribonucleic 
acid; DNP: 2,4-Dinitrophenyl; ECL: Enhanced chemiluminescence; ELISA: Enzyme-linked immunosorbent assay; FAB: Fast atom bombardment: FF: Fucofuroeckol-b; FT-IR: Fourier-transform infrared; HPLC: Highperformance liquid chromatography; IRES: Internal ribosome entry site; LC: Liquid chromatography; MCA: 7-Methoxycoumarin-4-yl acetyl; MEM: Modified Eagle's medium; MTT: 3-(4,5-Dimethylthiazol-2-yl)-2,5-diphenyl tetrazolium bromide; NMR: Nuclear magnetic resonance; ODS: Octadecylsilane; PVDF: Polyvinylidene fluoride; Q-TOF-MS: Quadrupole time-of-flight mass spectrometry; RFU: Relative fluorescence units; RNS: Reactive nitrogen species; ROS: Reactive oxygen species; RTPCR: Reverse transcription polymerase chain reaction; SAPP 3 : Soluble-APP SDS: Sodium dodecyl sulfate; SEM: Scanning electron microscope; SPE: Solid phase extraction; SPSS: Statistical package for the social sciences; TBST: Trisbuffered saline with Tween20; TLC: Thin layer chromatography; TOF: Time-offlight; UV: Ultraviolet visible

\section{Acknowledgements}

This research was supported by the Marine Biotechnology Program of the Korea Institute of Marine Science and Technology Promotion (KIMST) funded by the Ministry of Oceans and Fisheries (MOF) (No. 20140441).

\section{Funding}

The design of the study; collection, analysis, and interpretation of the data and writing of the manuscript were funded by a grant from the Ministry of Oceans and Fisheries (MOF) (No. 20140441).

\section{Availability of data and materials}

All datasets generated during and/or analyzed during the current study are available from the corresponding author on reasonable request.

\section{Authors' contributions}

HGB and LJK conceived and designed the study and helped to draft the manuscript and revised the manuscript. LJK performed the experiments, analyzed the data, and drafted the manuscript. All authors read and approved the final manuscript.

\section{Ethics approval and consent to participate}

Not applicable.

\section{Consent for publication}

Not applicable.

\section{Competing interests}

The authors declare that they have no competing interests.

\section{Publisher's Note}

Springer Nature remains neutral with regard to jurisdictional claims in published maps and institutional affiliations.

\section{Received: 30 October 2018 Accepted: 5 December 2018}

Published online: 28 December 2018

\section{References}

Artan M, Li Y, Karadeniz F, Lee SH, Kim MM, Kim SK. Anti-HIV-1 activity of phloroglucinol derivative, 6, 6'-bieckol. from Ecklonia cava. Bioorgan Med Chem. 2008;16:7921-6.

Athukorala Y, Lee KW, Kim SK, Jeon YJ. Anticoagulant activity of marine green and brown algae collected from Jeju Island in Korea. Bioresour Technol. 2007;98:1711-6.

Burtin P. Nutritional value of seaweeds. EJEAFChe. 2003;2:498-503.

Cornish-Bowden A, Eisenthal R. Statistical considerations in the estimation of enzyme kinetic parameters by the direct plot and other methods. Biochem J. 1974;139:721-30

Crouch PJ, Harding SME, White AR, Camakaris J, Bush Al, Masters CL. Mechanisms of $A \beta$ mediated neurodegeneration in Alzheimer's disease. Int J Biochem Cell Biol. 2008:40:181-98.

Durrenberger PF, Fernando FS, Magliozzi R, Kashefi SN, Bonnert TP, Ferrer I, Reynolds R. Selection of novel reference genesfor use in the human central nervous system: a BrainNet Europe Study. Acta Neuropathol. 2012;124:893-903.

Ghosh AK, Brindish M, Tang J. Developing $\beta$-secretase inhibitors for treatment of Alzheimer's disease. J Neurochem. 2012;120:71-83.
Glombitza KW, Gerstberger G. Phlorotannins with dibenzodioxin structural elements from the brown alga Eisenia arborea. Phytochemistry. 1985;24:543-51.

Heo SJ, Park EJ, Lee KW, Jeon YJ. Antioxidant activities of enzymatic extracts from brown seaweeds. Bioresour Technol. 2005;96:1613-23.

Jämsä $A$, Belda O, Edlund M, Lindstrom E. BACE-1 inhibition prevents the $\gamma$ secretase inhibitor evoked $A \beta$ rise in human neuroblastoma SH-SY5Y cells. J Biomed Sci. 2011;18:76

Johnston JA, Liu WW, Coulson DTR, Todd S, Murphy S, Brennan S, Passmore AP. Platelet $\beta$-secretase activity is increased in Alzheimer' disease. Neurobiol Agin. 2008;29:661-8.

Jung HA, Oh SH, Choi JS. Molecular docking studies of phlorotannins from Eisenia bicyclis with BACE1 inhibitory activity. Bioorg Med Chem Lett. 2010;20:3211-5.

Kang HS, Chung HY, Jung JH, Son BW, Choi JS. A new phlorotannin from the brown alga Ecklonia stolonifera. Chem Pharm Bull. 2003;51:1012-4.

Khan SB, Kong CS, Kim JA, Kim SK. Protective effect of Amphiroa dilatata on ROS induced oxidative damage and MMP expressions in HT1080 cells. Biotechnol Bioprocess Eng. 2010;15:191-8.

Kim MM, Rajapakse N, Kim SK. Anti-inflammatory effect of Ishige okamurae ethanolic extract via inhibition of NF-KB transcription factor in RAW 2647 cells. Phytother Res. 2009;23:628-34.

Kong CS, Kim JA, Yoon NY, Kim SK. Induction of apoptosis by phloroglucinol derivative from Ecklonia cava in MCF-7 human breast cancer cells. Food Chem Toxicol. 2009;47:1653-8.

Kousaka K, Ogi N, Akazawa Y, Fujieda M, Yamamoto Y, Takada Y, Kimura J. Novel oxylipin metabolites from the brown alga Eisenia bicyclis. J Nat Prod. 2003;66: 1318-23.

Kurata K, Taniguchi K, Shiraishi K, Suzuki MA. C26 sterol from the brown alga Eisenia bicyclis. Phytochemistry. 1990;29:3678-80.

Li Y, Lee S, Le Q, Kim M, Kim S. Anti-allergic effects of phlorotannins on histamine release via binding inhibition between IgE and FceRl. J Agr Food Chem. 2008:56:12073-80.

Masters CL, Selkoe DJ. Biochemistry of amyloid $\beta$-protein and amyloid deposits in Alzheimer disease. Cold Spring Harb Perspect Med. 2012;2:a006262.

Murphy MP, LeVine H. Alzheimer's disease and the amyloid-beta peptide. J Alzheimers Dis. 2010;19:311-23.

Noda H, Amano H, Arashima K, Hashimoto S, Nishizawa K. Studies on the antitumor activity of marine algae. Bull Jpn Soc Sci Fish. 1989;55:1254-64.

Okada Y, Ishimaru A, Suzuki R, Okuyama T. A new phloroglucinol derivatives from the brown alga Eisenia bicyclis: potential for the effective treatment of diabetic complications. J Nat Prod. 2004;67:103-5.

Ragan MA, Glombitza KW. Phlorotannins, brown algal polyphenols. Prog Phycol Res. 1986:4:177-241.

Ryu JK, Franciosi S, Sattayaprasert P, Kim SU, McLarnon JG. Minocycline inhibits neuronal death and glial activation induced by $\beta$-amyloid peptide in rat hippocampus. Glia. 2004:48:85-90

Shin $\mathrm{HC}$, Hwang $\mathrm{HJ}$, Kang $\mathrm{KJ}$, Lee $\mathrm{BH}$. An antioxidative and anti-inflammatory agent for potential treatment of osteoarthritis from Ecklonia cava. Arch Pharm Res. 2006:29:165-71.

Šimić G, Babić Leko M, Wray S, Harrington C, Delalle I, Jovanov-Milošević N, Bažadona D, Buée L, de Silva R, Di Giovanni G, Wischik C, Hof PR. Tau protein hyperphosphorylation and aggregation in Alzheimer's disease and other tauopathies, and possible neuroprotective strategies. Biomolecules. 2016;6:6.

Zarros A. In which cases is neuroprotection useful. Adv Altern Think Neurosci. 2009;1:3-5

Ready to submit your research? Choose BMC and benefit from:

- fast, convenient online submission

- thorough peer review by experienced researchers in your field

- rapid publication on acceptance

- support for research data, including large and complex data types

- gold Open Access which fosters wider collaboration and increased citations

- maximum visibility for your research: over $100 \mathrm{M}$ website views per year

At BMC, research is always in progress.

Learn more biomedcentral.com/submissions 